\title{
A spot test for detection of antibodies to phenolic glycolipid I
}

\author{
D B YOUNG, ${ }^{*}$ MELINDA J FOHN,* \\ SAROJ R KHANOLKAR* \& T M BUCHANAN*† \\ * Immunology Research Laboratory, Pacific Medical Center, \\ University of Washington, Seattle WA 98144, USA; † National \\ Hansens Disease Center, Carville LA 70721, USA
}

Accepted for publication 5 March 1985

\begin{abstract}
Summary A novel spot test for detection of antibodies to phenolic glycolipid I of Mycobacterium leprae has been developed. This test uses antigen-coated filter strips with a simple non-quantitative visual readout. Results of the spot test were in good agreement with those obtained using a standard microtitre ELISA test for antibodies with the new test being slightly less sensitive than the standard method. The spot test may be useful as a field test for serodiagnosis of leprosy in areas where microtitre plates, spectrophotometers and multichannel pipettes are not readily available.
\end{abstract}

\section{Introduction}

Several groups have recently described tests for detection of antibodies directed to the major phenolic glycolipid of Mycobacterium leprae ${ }^{1,2,3}$ which contains a trisaccharide portion unique to these organisms. ${ }^{4}{ }^{5}$ Sera from leprosy patients contain antibodies which specifically recognize the phenolic glycolipid with antibody levels increasing from the tuberculoid to the lepromatous pole of the leprosy spectrum. ' 2. 3 Control sera and sera from patients with other mycobacterial infections are negative in these tests ${ }^{2,3}$ and the possible use of such assays for the early detection of leprosy has been discussed.2. 6

The native glycolipid is a highly hydrophobic molecule and a variety of strategies have been employed to prepare aqueous suspensions suitable for the coating of the antigen to plastic microtitre plates and use in enzyme-linked immunosorbent assays (ELISA). These strategies include sonication ${ }^{2}$ or detergent solubilization' of the intact lipid, and partial hydrolysis of the lipid to produce the more polar deacylated form of the molecule. ${ }^{3}$ Synthetic antigens containing the antigenically important terminal di-methyl glucose residue ${ }^{7,8}$ have 
also been prepared and shown to be highly effective substitutes for the natural glycolipid in ELISA tests. ${ }^{9}$

A common feature of all of these assays is the use of microtitre systems employing disposable plastic multiwell plates. While such systems are extremely convenient for processing large numbers of samples, the plastic ware, multichannel pipettes and spectrophotometers required for the assays are often unavailable in the areas in which leprosy is endemic. We have therefore developed an alternative test for antibodies to phenolic glycolipid which does not utilize microtitre plates and gives a simple qualitative visual readout.

\section{Materials and methods}

\section{PREPARATION OF STRIPS}

Polysulphone membranes were supplied as HT-200 Tuffryn ${ }^{\circledR}$ Membrane Filters by Gelman Sciences Inc., Ann Arbor, Michigan. Membranes were cut into suitably-sized strips for the particular size of test tube selected for the assay. We have used either short strips $(1 \mathrm{~cm} \times 0.5 \mathrm{~cm})$ or long strips $(5 \mathrm{~cm} \times 0.5 \mathrm{~cm})$ with identical results. Phenolic glycolipid I was purified from infected armadillo tissue as described previously ${ }^{3}$ and dissolved in hexane at a concentration of 50 micrograms per ml. A single 2 microlitre drop was applied to the end of each filter strip (100 ng glycolipid per spot) and allowed to dry for a few minutes at room temperature. Strips stored for 2 months at $0^{\circ} \mathrm{C}$ or $37^{\circ} \mathrm{C}$ showed no loss in reactivity.

\section{SPOT TEST}

Strips were rinsed briefly with phosphate buffered saline $\mathrm{pH} 7 \cdot 2$ (PBS) and then immersed in tubes containing $1 \mathrm{ml}$ of PBS with $1 \%(\mathrm{v} / \mathrm{v})$ normal goat serum (Gibco Labs., Grand Island, NY) and 5 microlitres of human serum samples. With long strips, only the end of the strip with the glycolipid spot was immersed. Strips were incubated with antibody for $1 \mathrm{hr}$ at $37^{\circ} \mathrm{C}$ and then washed 4 times (5 min each wash) with $1.5 \mathrm{ml}$ of PBS per tube. Peroxidase-conjugated goat anti-human immunoglobulins ( $\operatorname{Ig} \mathrm{A}+\mathrm{IgG}+\mathrm{IgM})$ (Cappel Laboratories, Cochranville, $\mathrm{Pa}$ ) was diluted $1: 2,000$ in PBS containing $1 \%$ normal goat serum and 1 $\mathrm{ml}$ was added to each tube. After $1 \mathrm{hr}$ at $37^{\circ} \mathrm{C}$, strips were again washed 4 times with PBS. Peroxidase substrate was prepared by dissolving 3,3'-diaminobenzidine (Sigma Chemical Co., St Louis, Mo) in $0.1 \mathrm{M}$ citrate buffer pH $5(0.5 \mathrm{mg} / \mathrm{ml}$ ) and adding hydrogen peroxide to a final concentration of $0.03 \%$. Strips were incubated with substrate solution for $10 \mathrm{~min}$ at room temperature and then washed with water and examined for colour formation. 


\section{MICROTITRE ELISA}

An ELISA test using the deacylated form of the phenolic glycolipid coated to microtitre plates was performed as described previously ${ }^{3}$ except that serum samples were used at a dilution of 1:200 and the peroxidase substrate (o-phenylenediamine) was prepared in citrate buffer $\mathrm{pH} 5$ rather than in PBS.

\section{Results}

When polysulphone strips were incubated with serum samples containing antibodies to phenolic glycolipid a spot of colour was seen at the point of application of the antigen. According to the intensity of the colour reaction, results were given a grading of: ' - ' no reaction, ' + ' faint spot, ' ++ ' distinct spot, ' +++ ' dark spot. Figure 1 shows an example of 12 sera graded according to this approximate scale.

\section{CONTROL SERA}

Sera from 20 normal individuals living in Seattle were negative by the microtitre ELISA with deacylated phenolic glycolipid $\left(\mathrm{A}_{492}<0 \cdot 10\right)$ and were also found to

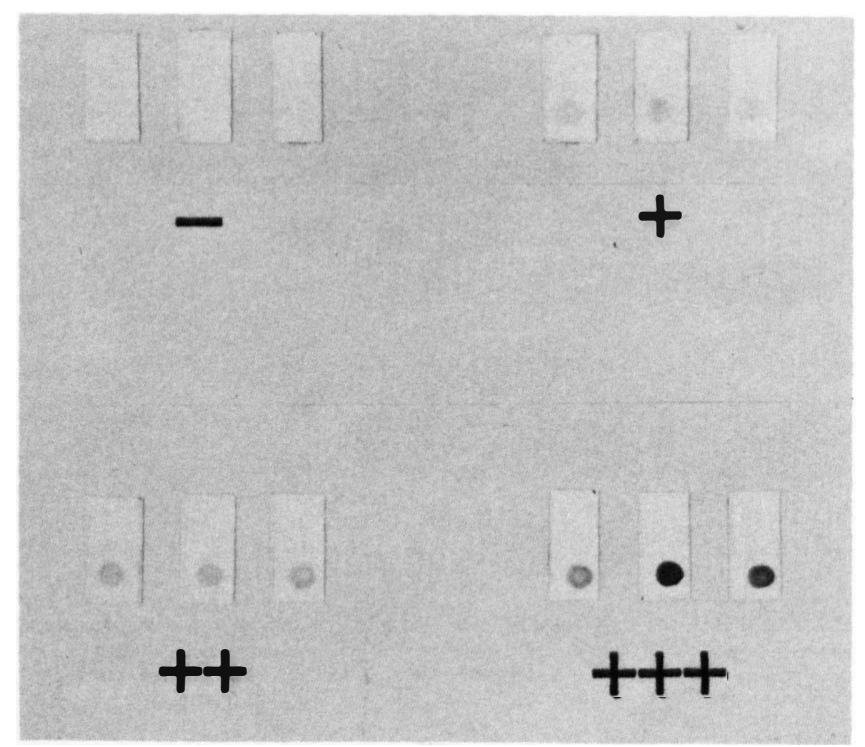

Figure 1. Results of the spot test with sera from leprosy patients.

Serum samples from 12 leprosy patients with different levels of antibodies to phenolic glycolipid I were assayed in the spot test as described in the text. Results were graded according to an approximate scale from ' - ' to ' +++ ' as shown. The antibody levels $\left(\mathrm{A}_{492}\right)$ recorded for the same sera in the microtitre ELISA were (left to right): ' - ' $0 \cdot 00,0 \cdot 02,0 \cdot 10$; ' + ' $0 \cdot 17,0 \cdot 19,0 \cdot 24$; ' $++^{\prime} 0 \cdot 49,0 \cdot 57,0 \cdot 65 ;$ ' $++{ }^{\prime}{ }^{\prime} 0 \cdot 88,1 \cdot 16,1 \cdot 18$. 
be negative in the spot test. Twenty-nine sera from tuberculosis patients were also tested and found to be negative in both tests.

\section{PATIENT SERA}

Eighty sera from leprosy patients with $\mathrm{A}_{492}$ readings in the microtitre ELISA ranging from 0 to 1.28 were assayed by the spot test and the results graded as described above. Figure 2 shows the spot test grading plotted against the absorbance in the microtitre ELISA. A good correlation between the 2 tests was observed. Sera which were negative in the spot test had absorbance values ranging from 0 to 0.19 with a mean value of 0.08 (standard deviation 0.06 ). Sera rated ' + ' had a mean of $0.29 \pm 0.14$; ' ++ ' $0.57 \pm 0.18$; and ' +++ ' $0.97 \pm 0.21$. An absorbance reading of less than $0 \cdot 10$ is considered negative in the microtitre ELISA $^{3}$ and all such sera were found to be negative in the spot test. All of the sera with $A_{492}$ of $0 \cdot 20$ or above were positive in the spot test. Of 17 sera with $A_{492} 0 \cdot 10$ to

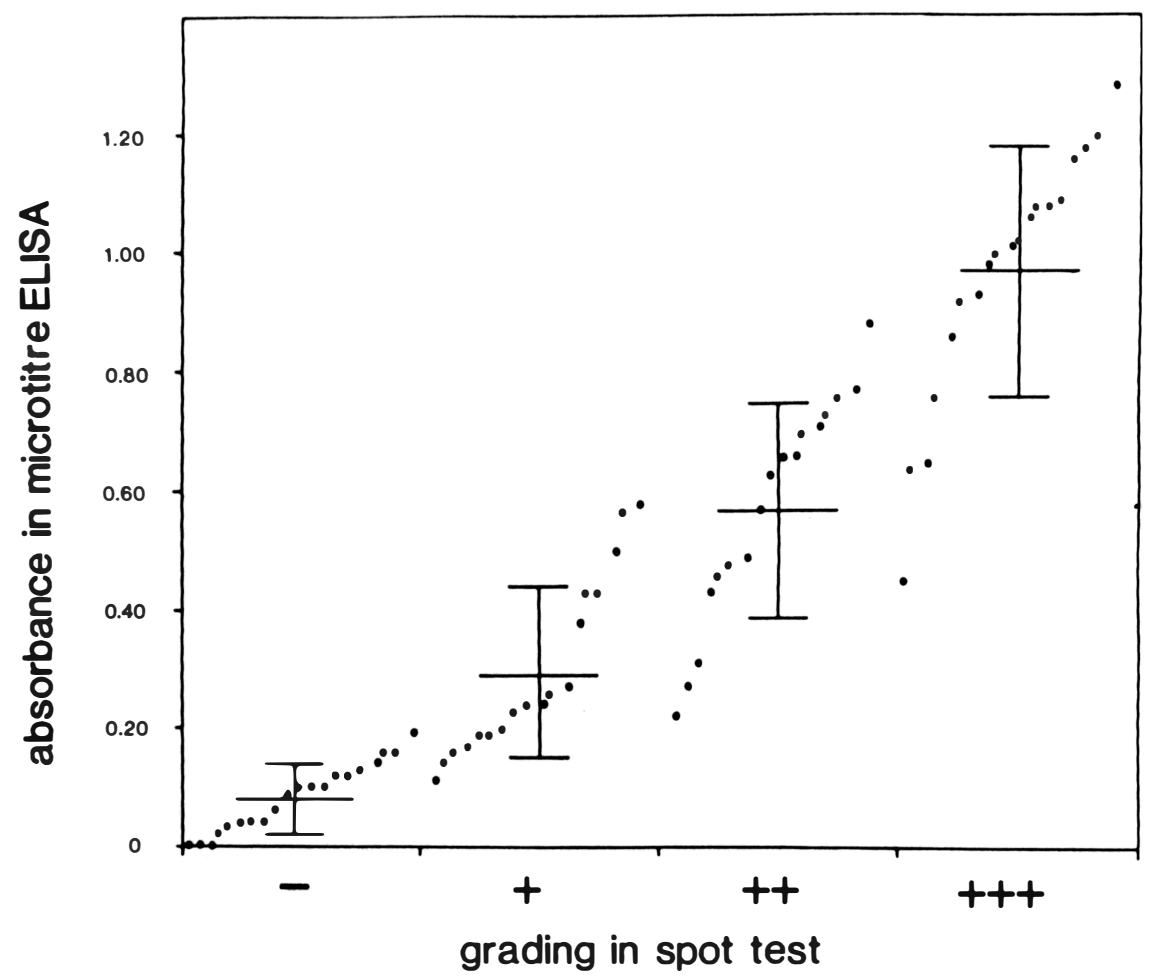

Figure 2. Comparison of the spot test and microtitre ELISA.

Eighty serum samples from leprosy patients were assayed at a dilution of $1: 200$ in the spot test and in the microtitre ELISA. Results are plotted as the $\mathrm{A}_{492}$ reading in the microtitre ELISA against the approximate grading in the spot test. Horizontal lines show the mean (and standard deviation) of $A_{492}$ readings for the sera graded in each category of the spot test. 
$0 \cdot 19,7$ were positive (' + ') by the spot test. Thus 10 sera which were considered positive by the microtitre ELISA were rated negative by the spot test.

\section{VARIATIONS IN THE ASSAY PROCEDURE}

While all of the results presented here represent those with serum samples assayed using the standard conditions described above, it was found that comparable results could be obtained using alternative procedures. Incubation of samples at room temperature $\left(20-25^{\circ} \mathrm{C}\right)$ was as effective as incubation at $37^{\circ} \mathrm{C}$ and tap water could be substituted for PBS during the washing steps. Plasma prepared from blood collected in the presence of heparin gave identical results to serum from the same individual. Whole blood either diluted directly into PBS or dried on filter paper and then resuspended in PBS could also be used in the assay. Antibodies to phenolic glycolipid could also be detected in saliva samples using the spot test.

\section{Discussion}

The spot test described here differs from previous tests for antibodies to phenolic glycolipid in that it does not require the use of disposable microtitre plates. The solid support used for binding the glycolipid is a polysulphone membrane which was selected on the basis of its low level of background binding of IgM antibodies. ${ }^{10}$ The test tubes used for carrying out reactions can be washed and reused for further assays with fresh antigen strips. This feature of the test may make it convenient for use in areas where microtitre equipment is not available.

The results of the test are read by looking for a coloured spot against a white background. For a test involving a non-quantitative visual readout, it was found to be easier to distinguish a coloured spot rather than to judge differences in formation of a soluble coloured product such as that used in the microtitre ELISA tests. In addition, results of this test were not affected by any differences in non-specific binding of serum antibodies to the solid support since any such interactions result only in a darkening of the background colour which is readily distinguished from binding to the antigen spot.

The results of the test were in good agreement with those of the standard microtitre ELISA although sera with very low positive antibody levels $\left(\mathrm{A}_{492}\right.$ $<0.20)$ were not uniformly detected as positive in the spot test. This observation suggests that the spot test is less sensitive than the microtitre ELISA. Large scale screening of household contacts of leprosy patients in Mexico and in Sri Lanka suggests that these low positive antibody levels are common amongst individuals exposed to $M$. leprae but having no evidence of clinical disease. ${ }^{6}$ The spot test may therefore be less useful in detection of exposure to $M$. leprae but will be useful for identification of individuals with higher antibody levels associated with the development of the lepromatous form of leprosy. 
It is not envisaged that the spot test will replace standard microtitre ELISA tests for antibodies to phenolic glycolipid. These tests have clear advantages from the point of view of conducting large scale epidemiology studies of leprosy exposure and infection. In small scale field studies, however, the simpler and more flexible spot test may provide a useful alternative for workers who do not have appropriate facilities for conducting the microtitre tests.

\section{Acknowledgements}

This research was supported in part by grants from the IMMLEP and THELEP components of the UNDP/WHO/World Bank Special Program for Research and Training in Tropical Diseases, by a grant from the Rockefeller Foundation Program for Research on Great Neglected Diseases and by grant \#Y01-AI - 40008 from the INDO-US Science and Technology Initiative through the NIAID, NIH.

\section{References}

' Brett, SJ, Draper, P, Payne, SN, Rees, RJW. Serological activity of a characteristic phenolic glycolipid from Mycobacterium le prae in sera from patients with leprosy and tuberculosis. Clin Exp Immunol, 1983; 52: 271.

${ }^{2}$ Cho, SN, Yanagihara, DL, Hunter, SW, Gelber, RH, Brennan, PJ. Serological specificity of phenolic glycolipid I from Mycobacterium leprae and use in serodiagnosis of leprosy. Infect Immun, 41: 1077.

${ }^{3}$ Young, DB, Buchanan, TM. A serological test for leprosy with a glycolipid specific for Mycobacterium leprae. Science, 221: 1057.

${ }^{4}$ Hunter, SW, Brennan, PJ. A novel phenolic glycolipid from Mycobacterium leprae possibly involved in immunogenicity and pathogenicity. J Bacteriol, 147: 728.

${ }^{5}$ Hunter, SW, Fujiwara, T, Brennan, PJ. Structure and antigenicity of the major specific glycolipid antigen of Mycobacterium leprae. J Biol Chem, 1982; 257: 15072.

${ }^{6}$ Buchanan, TM, Dissanayake, S, Young, DB, Miller, RA, Acedo, JR, Harnisch, JP, Khanolkar, SR, Estrada-Parra, S. Evaluation of the significance of antibodies to phenolic glycolipid of Mycobacterium leprae in leprosy patients and their contacts. Int. J Lepr, 51: 658.

7 Fujiwara, T, Hunter, SW, Cho, SN, A spinall, GO, Brennan, PJ. Chemical synthesis and serology of the disaccharides and trisaccharides of phenolic glycolipid antigens from the leprosy bacillus and preparation of a disaccharide protein conjugate for serodiagnosis of leprosy. Infect Immun, 1984; 43: 245.

8 Young, DB, Khanolkar, SR, Barg, LL, Buchanan, TM. Generation and characterization of monoclonal antibodies to the phenolic glycolipid of Mycobacterium leprae. Infect. Immun, 1984; $43: 183$.

9 Cho, SN, Fujiwara, T, Hunter, SW, Rea, TH, Gelber, RH, Brennan, PJ. Use of an artificial antigen containing the 3,6-di-O-methyl-D-glucopyranosyl epitope for the serodiagnosis of leprosy. J Infect Dis, 1984; 150: 311.

10 Young, DB, Fohn, MJ, Buchanan, TM. Use of a polysulfone membrane support for immunochemical analysis of a glycolipid from Mycobacterium leprae. J. Immunol. Methods, 1985; 79: 205. 